\title{
Spatial Spillover Effects of Economic Growth Based on High-Speed Railways in Northeast China
}

\author{
Haoming Guan (iD) ${ }^{1}$ and Qiao $\mathrm{Li} \mathbb{( i D}^{2}$ \\ ${ }^{1}$ School of Geographical Sciences, Northeast Normal University, 5268 Renmin Street, Changchun 130024, China \\ ${ }^{2}$ School of Architecture and Design, Changchun Institute of Technology, 3066 Tongzhi Street, Changchun 130021, China \\ Correspondence should be addressed to Qiao Li; liq869@nenu.edu.cn
}

Received 18 August 2020; Revised 18 December 2020; Accepted 3 March 2021; Published 1 April 2021

Academic Editor: Wen-Ze Yue

Copyright ( 2021 Haoming Guan and Qiao Li. This is an open access article distributed under the Creative Commons Attribution License, which permits unrestricted use, distribution, and reproduction in any medium, provided the original work is properly cited.

\begin{abstract}
This paper examines the spatial spillover effects of public transportation infrastructure on regional economy in Northeast China, the "rust belt" region in China. The dataset consists of socioeconomic data from 47 cities in the area during the period of year 2005 through 2015. Accessibility is used as an explanatory variable to reflect the influence of infrastructure on economic development. In order to avoid the endogenous, queen contiguity matrix is used to define the spatial weight matrix. In the paper, the dynamic panel data model is also used to explore the effects of high-speed railways in the whole study area and attempted to confirm the spatial differences among Heilongjiang Province, Jilin Province, and Liaoning Province. The results show that the high-speed railways increase the cities' connection in terms of accessibility, and a significant positive spillover effect exists after the construction of high-speed railways (HSR), indicating the extensive economic benefits of HSR construction, despite of the overall economic difficulty experienced by this region.
\end{abstract}

\section{Introduction}

China has developed dramatically in the past few decades, with an average $10 \%$ growth rate over the past 30 years [1]. However, the development is geographically unbalanced especially between the east coast and the inland area [2]. Several reasons may have contributed to this phenomenon: first, most economic policies implemented by the central government favor cities in coastal areas; second, the east coast enjoys great locational advantage [3], and its accessibility to both inland resources and ports makes it attractive in the global economy [4]; third, the development of transportation infrastructure in this region may have played a key role in enabling the spatial spillover of economic development and hence agglomeration, implying further industrial and population clustering [5].

In contrast, the economic development in Northeast China has fallen behind. As the old base of heavy industrial, the northeast region has suffered from population loss and very low (and even negative in recent years) economic growth rate [6]. Many believe that this region's over-reliance on natural resources and heavy industry is the main contributing factor [7]. Seeing the success of the east coast, the Chinese central government started a series of policies to stimulate the economy of the Northeast region. One of these key policies was to invest in infrastructure and expand public transportation especially the high-speed rail (HSR) in this region. It was expected that public transportation enables to serve larger markets much more economically to make the market potential enlarged [8]. The enhanced market potential increases cities connectivity caused by transportation systems [9].

Historically, the northeast region had reasonably good transportation infrastructure. The Chinese Eastern Railway helps carry the trade flow between China and Russia and promoted the regional economy. The T-shaped line consisted of three branches of railways: the western branch, referring to the Harbin-Manzhouli Railway, the eastern branch, now the Harbin-Suifenhe Railway, and the southern branch, which has become a part of the Beijing-Harbin 
Railway [10]. The proposed HSR under this stimulation policy, the Harbin-Dalian (Ha-Da) HSR, was built along this Chinese Eastern Railway. The total length of this HSR is 921 kilometers with 24 stations, connecting 9 main cities in the region. This HSR began its construction phase on August 23, 2007, and was put into operation on December 1, 2012.

However, some research explored that Harbin-Dalian HSR has positive effects on the tourism industry [11], but the economic development in the northeast region did not seem to show any clear trend of improvement after the operation of HSR. Doubt had been casted on the effect of infrastructure investment in such an economically difficult region. The purpose of this paper is thus to examine the effect of HSR on the regional economy considering the influence of other factors at the same time. There has been no lacking of studies on the effect of HSR in developed countries or regions. Nonetheless, its effect on economically challenging regions has been rarely investigate. By disentangling the effects of various factors, this paper identifies the effect of HSR and assesses the influence of the stimulation policy in a quantitatively rigorous way.

\section{Literature Review}

2.1. Measurement of Transportation Conditions: Accessibility. The transportation condition can be measured in different ways. Some simplified metrics are the number or density of road segments, intersections, and stations. The more sophisticated approach, which has been adopted by many studies, is the index of accessibility. Hansen came up with the traditional definition of accessibility as the potential for opportunities of interaction [12]. Accessibility was defined as the convenience level that activities could be reached from one place by using some transport services [13]. Over years, accessibility has become a main metric measuring social and economic development in one region [14]. Many researchers regard accessibility as a concept of interaction activities [15-17]. Some popular definitions of accessibility are the weighted travel time, daily accessibility, and potential values $[18,19]$. Generally, accessibility calculation approaches mainly based on time or potential especially in the field of economy and connection between cities [20-22]. The time cost method is used in the field of microperspective mostly in one city, such as job accessibility or healthy accessibility [21,23-25]. Market potential is commonly used to be as an accessibility indicator from an economic perspective which is analyzing cities' correlation related to the mass of destination and inversely proportional to the distance and travel time [1]. Another method to calculate accessibility is in the synthetical perspective, time, cost, mass, and even price cost which refer to people's travel preference between different nodes, especially cities [26,27].

As a major change of transportation infrastructure, HSR is always related to change of accessibility. For example, Levinson [28] suggested that HSR and the consequent higher accessibility would increase total wealthy and lead to the redistribution of the wealth. In the recent decade, high-speed rail developed very fast in China, and it is proved that transportation influences the economic growth with the change of shortened travel time and reduced cost, which enhances the accessibility [29,30]. And, the accessibility always represents the location endowment of a city in one region transport network [31]. Then, once the location endowment is enhanced by developed transportation ways, it must prosper the economic growth effects. Some empirical results explain the mechanisms and process [32].

2.2. Spatial Spillover. With the infrastructure development, the unbalanced development of different areas caused by transport infrastructure such as HSR will cause externality on economy [33]. Many studies have attempted to quantity the spatial spillover effects of infrastructure since $1980 \mathrm{~s}$ [34-36]. The spatial spillover elasticity of railway investment was usually found positive [37-39]. The spillover impact of transport infrastructure stock was estimated by using spatial econometrics models and it was found the spillover effects of transport infrastructure existed at both national and regional level [40]. Arbués et al. analyzed the spatial productivity of transportation infrastructure in 47 Spanish provinces and provided strong evidence demonstrating the positive effects of road infrastructure projects on private economy [8]. Comber et al. suggested that accessibility could be used to measure the spillover effects of transport infrastructure [41]. However, not all spillovers imply positive effects on economy $[42,43]$. Negative spillover effects were indicated in the central region of China in 1991-2000 [40]. Moreno and Lopez-Bazo investigated the economic returns of transportation investment and found negative spillovers across Spanish areas [44]. In terms of methodology, spatial econometric modeling is the main approach used to quantify spatial spillover effects. Literature can be found in finance, geography, economy, and environment [45-49]. Researchers also explored the spatial dynamic panel data models to analyze variables lagged in space, in time, or in both space and time [50].

Beijing-Shanghai HSR runs through China's two most important economic zones (Yangtze River Delta and Beijing-Tianjin-Hebei region). The population along this railway covers more than a quarter of the national population. The core cities are often the gathering places of high-income groups and the demand for fast transportation is very high. In contrast, some intermediate-node cities with lower economic levels have much lower demand for fast transportation than core cities. Moreover, in order to maintain high-speed operation, the number of high-speed rail stations is relatively small compared to ordinary railways, and most of them are in cities with high demand for fast traffic. HSR mainly shortens the travel time and strengthens the connection of cities which improve regional market potential, especially in Yangtze River Delta. In Yangtze River Delta of China, as a labor and capital agglomeration typical area, on one hand, HSR mainly serves the secondary intermediate cities, on the other hand, HSR also impacts on travel times, accessibility and economic productive. In this area which has the highest density degree of HSR density in China, the travel cost is sharply shortened by HSR makes the mobility of factors such as population, technique, and information 
boost. In this case, a lot of manufacturing enterprises migrate from the core city to a medium or small city to reduce cost. Thus, it is obtained that HSR contributes to the flow of wealth and shorten time cost in this area. However, in the Beijing-Tianjin-Hebei region, the density of cities is not as high as the one is Yangtze River Delta. As the capital of China, Beijing and the Beijing-Tianjin-Hebei region mainly plays an administrative role, and its market functions are weaker than cities in the Yangtze River Delta region. But, in Beijing, there are lots of enterprises bases, so the region has a large flow of people and business contacts. HSR in this area principally provides a convenient corridor for people and information and even enhances knowledge spillovers.

Above all, Beijing-Shanghai HSR helps to improve the reachability in Beijing-Tianjin-Hebei region and then intensifies the political function of Beijing as a core city, contemporaneously, with the improved reachability; in Yangtze River Delta region, the market potential of the region increased. As a result, economic agglomeration attracts capital and labor, which has promoted the sustained growth of the regional economy. But, this study area is totally different from Beijing-Tianjin-Hebei region and Yangtze River Delta due to the people loss and the weakness of economy agglomeration. In this condition, whether HSR could contribute to regional economy is the critical issue in this paper. The study contributes to academic literature in several ways. First, from our observation, it is the first work to evaluate the economic benefits of HSR based on countylevel panel data of Northeast China. And, this paper tried to compare two periods with and without HSR in order to test HSR effect and compare the whole area and the three provinces to certify the differences. Second, although a few studies use difference-in-difference model to test the effect of HSR [51], this method is in the lack of spatial factors. Despite spatial econometrics models are popular to test the transportation infrastructure spatial effects [52], they lack the consideration of time lag effect. To compensate for the shortcomings of both approaches, this study works as a new example for using dynamic spatial econometrics models to evaluate the performance of HSR in economic growth including both time and spatial lag. Moreover, this study considers the region spatial heterogeneity in the analysis and finds that regions with different accessibility levels and location will benefit differently from the operation of HSR. Especially there have been old industrial bases in Northeast China which is totally different with other regions; this region with difficulties in economic transformation and relatively slow development is facing shortage of market power and large population loss. This paper focuses on what role the HSR plays on regional economic in these areas.

This paper is organized as follows: Section 2 summarizes existing literature on accessibility and spatial spillover effects. Section 3 consists of two parts; the first part introduces the spatial and dynamic spatial econometric methods and the second part examines the spatial autocorrelation of economic indexes. Section 4 describes data sources and the calculation of accessibility. Section 5 presents and interprets the model results, followed by conclusions.

\section{Methodology}

3.1. Accessibility Calculation. Due to the importance to choose a proper indicator for measuring the accessibility changes, it is considered that HSR makes labor flow and capital flow faster than before and shortens the spatial distance and time cost generally. And then cities along HSR get connected; thus, factor cost decreased which could lead economy growth to be positive agglomerated. However, HSR is not only known for its high speed but also for the ticket price. In addition to the time factor, passengers often consider the ticket price when choosing high-speed trains. In this case, the travel price factor is based on two scenarios, normal rail and high-speed rail costs. Therefore, this paper adopts the generalized weighted travel time accessibility calculation method from a synthetical perspective, which can comprehensively consider such factors as time, mass, and price, where the lower the value and the better the accessibility [53]. Therefore, the model is specified as follows:

$$
\begin{aligned}
A_{i j} & =\min \left[\frac{P_{j} \times T_{i j, k}}{\sum_{j=1}^{n} P_{j}}+\frac{F_{i j, k} / \mathrm{TV}_{j}}{\sum_{j=1}^{n}\left(1 / \mathrm{TV}_{j}\right)}\right], \\
\mathrm{TV}_{j} & =r \times \mathrm{TW}_{i} \times(1-r) \times \beta \times \mathrm{TS}_{j}, \\
\mathrm{TS}_{j} & =\frac{W}{\mathrm{WH}}, \\
A_{i} & =\sum_{j} A_{i j},
\end{aligned}
$$

where $A_{i j}$ is the extent accessibility between city $i$ and city $j$, $P_{j}$ is the total population of city $j, n$ is the number of sample, $\mathrm{GDP}_{j}$ is Gross Domestic Product of city $j, T_{i j, k}$ is the shortest travel time from node $i$ to node $j, F_{i j, k}$ is the lowest cost from $i$ to $j$ (in this paper, it is chosen according to general train price and high-speed rail second-class price), $\mathrm{TV}_{j}$ is the travel time value, $W$ is the urban per capita disposable income, and WH is 2000 according to the number of legal working time of a year in China. The travel time value of individual trip is set up to related to work trip. The ratio of time value between individual trip and work trip is chosen to be from 0.2 to 0.6 in China [26]. In this paper, $\beta$ is valued as 0.4 and $\alpha$ is valued as 0.6 [27].

3.2. Spatial Econometrics Models. The basic model form starts from the classic CobbDouglas (C-D) function $[54,55]$ so that

$$
Y=A L^{\alpha} K^{\beta}
$$

where $Y$ represents the economic output, measured with Gross Domestic Production (GDP), $L$ represents labor capital and $K$ represents capital, and $A$ is the total factor productivity. The log-linearized form is thus

$$
\ln Y=\beta_{0}+\beta_{1} \ln L+\beta_{2} \ln K+\varepsilon .
$$


The traditional regression model ignores the spatial interaction. Based on Tobler's First Law of Geography, when the distance between the geographical unit becomes shorter, the interaction becomes stronger. Generally, the spatial weight matrix is used to measure the spatial relationship. When considering the spatial effects, the model form will be

$$
y_{i t}=\alpha+\rho W y_{i t}+X_{i t} \beta+\theta W X_{i t}+\mu_{i}+\lambda_{t}+\varepsilon_{i t},
$$

where $\alpha$ is the constant term, $\rho$ is spatial correlation coefficient, $W$ is the spatial weight matrix, $X$ is the matrix of independent variables, $\beta$ and $\theta$ are vectors of regression coefficient estimates, $\varepsilon_{i t}$ is error term, $W y_{i t}$ and $W X_{i t}$ are spatial lagged variables, and $\mu_{i}$ and $\lambda_{t}$ are spatial specific effects and time period effects which can be included in order to represent spatial and temporal heterogeneity. When $\theta$ is zero, this model is called a spatial lag model (SLM), and when $\theta$ is not zero, it is called a spatial Durbin model (SDM).

The weight matrix $W$ reflecting the intensity of geographic relationship among all areas is vital in the spatial analysis [56]. There are queen's contiguity matrix [40], distance weight matrix, and first- and second-order matrices [57] and so on. In order to avoid of endogeneity, in this paper, contiguity matrix and geographic distance matrix are used to define the spatial weight matrix. If one city is not directly connected by HSR, the transferring time will be counted.

In summary, this paper uses the SLM model to measure the spillover effects, as outlined as follows, respectively:

$$
\ln y_{i t}=\alpha+\rho \sum_{j=1}^{11} W_{i j} \ln y_{i t}+\beta_{k} \sum_{k=1}^{9} \ln x_{k i t}+\mu_{i}+\lambda_{t}+\varepsilon_{i t} \text {. }
$$

To further consider the temporal dependence, temporally lagged terms are also added so that

$$
y_{i t}=\alpha+\gamma y_{(i, t-1)}+\eta W y_{(i, t-1)}+\rho W y_{i t}+X_{i t} \beta+\varepsilon_{i t},
$$

where $y_{(i, t-1)}$ is the dependent variable lagged in time and $W y_{(i, t-1)}$ is the dependent variable lagged in time and space.

\section{Data Description}

4.1. Data Source and Description. The study area includes 25 cities which are directly connected by HSR and 22 other neighboring cities of three provinces (Heilongjiang Province, Jilin Province, and Liaoning Province) in Northeast China, especially concentrating on Harbin Changchun Urban Agglomeration and Central and Southern Liaoning Urban Agglomeration [58]. The travel time between two cities before and after HSR construction are collected from the official website of 12306 China Railway. Other socioeconomic data are collected from the China City Statistical Yearbook, Heilongjiang Statistical Yearbook, Jilin Statistical Yearbook, and Liaoning Statistical Yearbook.

The dataset covers information for these 47 cities from 2005 to 2015. Theoretically, CobbDouglas (C-D) function shows that labor, capital, and technique as the direct factors contributing to economic growth. Empirically, in Northeast China, the economic growth is mainly driven by traditional factors, for instance, labor input, land investment, and infrastructure investments rather than up to innovation investment. As a result, in this study, we try to consider the two parts including labor and capital to explain economic growth. To the labor, employee number and urban population proportion influence the regional economic growth. The reasons are as follows: the traditional production process is in the demand of large number of employees. With the more labor input, the production output increases obviously. Also, the urban population proportion changing impacts on the consumption and residential building investment, and the two as the troika of economic growth will naturally influence on regional economic growth. To the capital, fixed assets investment is a traditional way and the main means of social reproduction in the process of economic growth. Moreover, as a marcoeconomic issue, the government power always plays an important role, and we would like to choose governmental expenditure as the indicator to present it.

Besides the control variables, a variable related to transportation condition, accessibility (ACC) which refers to the results calculated by equation (1) to equation (4) is added into the model to be as a mainly explanation variable. Altogether, these variables are used to identify the spatial spillover effects of economic growth [59-61]. The basic statistics of the key variables are listed in Table 1.

4.2. Spatial Pattern of Regional Economy. The spatial autocorrelation test is first used to examine the spatial pattern of regional economy in the study area. As shown in Table 2, all Moran's I values are above 0.29 , suggesting that the GDP of these cities present significant spatial correlation since 2005. In other words, in the northeast region, a city's GDP is interrelated with the adjacency area. Moran's I value does not change much over years, with a slightly decreasing tendency after 2011 potentially because that various areas started to take dissimilar measures to develop their own advantageous industry in recent years. Nevertheless, Moran's $I$ values indicate the existence of spatial correlation and justify the use of spatial econometric models.

Figure 1 further explores the different correlation pattern of these cities' GDP. The two figures summarized each city's spatial correlation pattern in years 2005 and 2015, respectively.

Main cities directly connected by HSR, especially the capital cities, are in the first quadrant in both 2005 and 2015. This indicates that GDP values tend to be high in these cities and also their surrounding cities. Cities in these second quadrants tend to have relatively lower GDP than adjacent cities. From the geographic distribution, these cities are usually far away from the main cities and their accessibility is low. Cities in the third quadrant are those whose own GDP and their surrounding area's GDP are low. Most of these cities are county-level cities. GDP is low mainly due to the small scale of the city. Cities in the fourth quadrant are the ones that have better economy than their surrounding cities. Yingkou is the only city falling in this quadrant.

The comparison of the two charts suggests that the disparity of economic development in different cities has 
TABLe 1: Data description and statistics.

\begin{tabular}{|c|c|c|c|c|c|}
\hline Name & Definition & Mean & Standard deviation & Min & Max \\
\hline \multicolumn{6}{|c|}{ Dependent variable } \\
\hline \multicolumn{6}{|c|}{ Independent variables } \\
\hline INV & Fixed asset investment (million yuan) & $3.668 * 10^{4}$ & $6.629 * 10^{4}$ & 233.570 & $4.427 * 10^{5}$ \\
\hline GOV & Government expenditure (10 thousand yuan) & $4.647 * 10^{5}$ & $7.970 * 10^{5}$ & $2.901 * 10^{4}$ & $5.703 * 10^{6}$ \\
\hline URB & Urban population proportion (\%) & 37.8 & 77.1 & 10.6 & 81.8 \\
\hline EMP & Employee number (million person) & 21.404 & 0.106 & 1.007 & 197.371 \\
\hline $\mathrm{ACC}$ & City accessibility calculated by cost, travel time, and city scale & 362.889 & 129.839 & 77.1939 & 659.36 \\
\hline
\end{tabular}

TABLE 2: Moran' I value of GDP in Northeast China.

\begin{tabular}{lccc}
\hline year & Moran's $I$ & $Z$ value & $P$ value \\
\hline 2005 & 0.31 & 2.98 & 0.005 \\
2006 & 0.30 & 2.74 & 0.017 \\
2007 & 0.29 & 2.75 & 0.016 \\
2008 & 0.29 & 2.91 & 0.013 \\
2009 & 0.30 & 2.72 & 0.013 \\
2010 & 0.29 & 3.02 & 0.010 \\
2011 & 0.31 & 2.92 & 0.009 \\
2012 & 0.32 & 3.07 & 0.007 \\
2013 & 0.31 & 2.91 & 0.005 \\
2014 & 0.30 & 2.97 & 0.008 \\
2015 & 0.29 & 2.96 & 0.014 \\
\hline
\end{tabular}
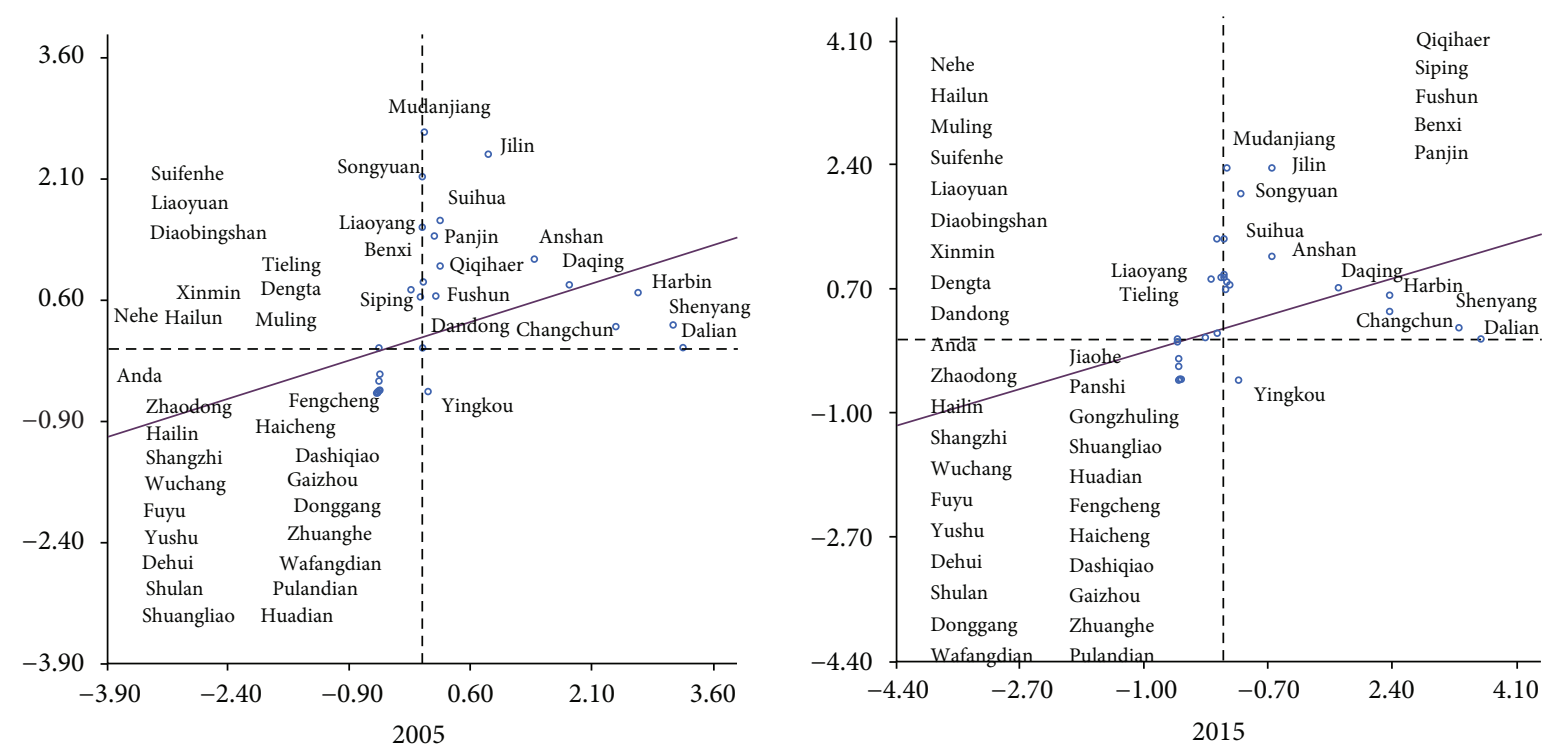

Figure 1: Moran Plot of GDP in Northeast China in year 2005 and 2015.

increased over years. Cities with HSR and high accessibility seem to develop faster than others. However, it is hard to tell how much of this development disparity should be attributed to labor and capital factors with just Moran plots.

4.3. Transportation Condition. As stated in existing research, the change of accessibility is a direct consequence of transportation improvement [62]. The definition of accessibility above is based on the improvement of the market potential which is closely related to "new economic geography". When changes happen to transport costs, the accessibility of one city will also change. Because of the imperfectly competitive market, economic activities and industry agglomeration will be influence in this case. Then, the agglomeration phenomenon impacts on economic productivity and potential benefits. In this paper, if the accessibility is low, the reachability is high. It is regarded as an indicator to describe the reachability of one city. 
In order to more intuitively compare high-speed rail based and normal trains, the spatial distribution of urban accessibility levels is described by natural breaks by ArcGIS as shown in Figure 2. The cities of Qiqihaer, Anda, Zhaodong, Hailin, Dehui, Yushu, Wuchang, Jilin, Shulan, Gongzhuling, Siping, Dengta, Benxi, Haicheng, Dashiqiao, Wafangdian, and Pulandian have higher reachability. The low-value accessibility areas include Jiaohe, Shuangliao, Panshi, Fengcheng, and Dandong.

The number of high reachability in cities based on highspeed rail turns out to be larger. Among them, the number of cities with high degree of proximity has increased significantly, namely, Daqing, Harbin, Changchun, Jilin, as well as cities in Liaoning Province including Shenyang, Anshan, Dengta, Benxi, Panjin, Liaoyang, Haicheng, Dashiqiao, Donggang, Wafangdian, Pulandian, and Dalian, accounting for $50 \%$ of the total number of samples. These cities are mainly concentrated in areas along the high-speed rail. The medium-high value areas are mainly distributed in the peripheral areas of cities along the HSR railway. In the area of Heilongjiang and Jilin Province, the accessibility of the city has a more obvious core-edge spatial distribution pattern. Since the high-speed railway connecting east-west direction has not been opened, the reachability of the eastern region is at a low level, and the low-value cities are Nehe, Shangzhi, Hailun, Fuyu, Shuangliao, Panshi, and Fengcheng, the only one city from Liaoning Province.

Based on the above spatial analysis, the opening of highspeed rail has greatly improved the reachability of cities in Liaoning Province. Due to the high density of cities in the region, the distance between cities with high-speed rail is relatively short, and the high-speed rail has greatly reduced the travel time.

\section{Results Analysis}

In addition to logarithmic transformation, the study uses the difference method in data processing in order to avoid multicollinearity. Therefore, the regression results reflect the effect of growth rate of every variable.

This paper compares several different models. The first step is to choose fixed effect or random effect by the Hausman test. Then, the second step is to confirm whether it is time-fixed effect or spatial-fixed effect. The result in terms of the Hausman test shows that two period $t$ statistics values pass the $1 \%$ and $10 \%$ significant levels which support to refuse the null hypothesis. So, it is reasonable to choose fixed effect. Third, there are three fixed effects in total to be used to estimate the spatial econometrics. This paper adopts the LR test joint significance to confirm the fixed effect. According to the LR test, because all the results pass the significant level test, it means time and spatial fixed effect should be used for the following models.

Table 3 shows the results of regression. It is observed that the coefficients associated with the two period models are similar but the significance level seems different. To be more detailed, most of the independent variable coefficients are positive except for the employee number and accessibility; however, it is kept the same with the definition of accessibility mentioned above. That means, if the accessibility is high, it will cost more to connect to other cities which could improve the market cost. In this region, the employee is mainly working in the state-owned enterprises sector, and this enterprise structure is stabilization. As a past prosperous industry base, the GDP growth in the region mainly relies on the industry value not the labor or talent gathering. For a long time, the region serves as an energy base and commodity grain base, and there are many people who are engaging in farm, mining, and forest. Due to the stable structure, it is difficult for economy transformation from resource-based to innovation-based ones. In this case, the significance turns to be not visible.

With time went by, the significance level of investment increased to $5 \%$. It is evident that the independent variables with spatial lag are significant which implies that most of the inputs have spatial spillovers effects. This means one area is affected by the around area. Comparing two periods, it is obtained that the significance of spatial lagged variables increased including the investment, accessibility, and urbanization. However, the significance of government control spatial lagged variable decreased. Mainly due to the connection leaded by the HSR, the railway between cities increasing can shorten the cost especially time cost; this could make two different cities market get closer. Furthermore, industry and other resource agglomeration occur because of the closer market which is beneficial to regional economic growth.

The opening of HSR has made the core cities such as Harbin, Changchun, Shenyang, and Dalian more economically connected, playing different roles in leaders, exporters, and intermediaries among the intraregional economic connection network. The closer economic connection of the space is conducive to promoting the development of the urban economic linkage network structure in the northeast region to a more stable direction, highlighting the role of growth in regional economic growth.

Table 4 further summarizes the results of the dynamic model in different areas. When sampled among the whole area, considering all the lagged items by time and spatial, the coefficient of the dependent variable lagged in time and the one in both time and spatial are positive and statistically significant at the $5 \%$ level. This means that the dependent variable lagged in time and both in time and spatial effect on the whole study area GDP growth. When this variable extends 100 units, it increases the GDP growth to 10 units and 4 units. Moreover, the one lagged in spatial of GDP growth is spatial not only positive but also statistically significant at the $5 \%$ level test calculated with contiguity matrix. In the whole area, the GDP growth tends to be positive spatial effect on neighboring area. Results from the dynamic models further confirm that spillover effects of GDP growth do exist. Investment, government control, and employee population are positive and significant at $1 \%$ level, but accessibility is negative and significant. In the whole study area, for a relatively long period, economic growth chiefly is driven by amount of investment and resource utility. Thus, the investment and labor contribution play an important role in economic growth dramatically. 


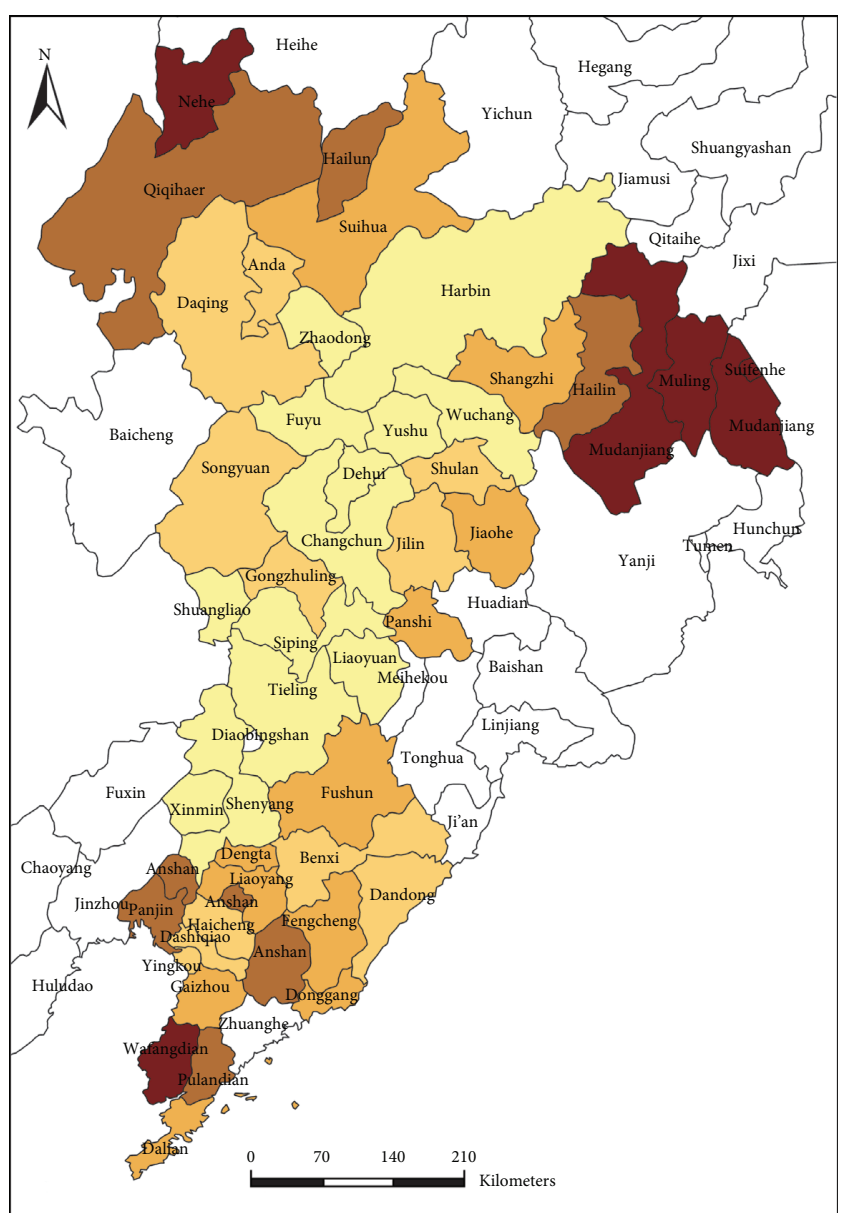

Study area

$\square 259.688834$ - 336.674331

$336.674332-410.457448$

410.457449 - 464.423131

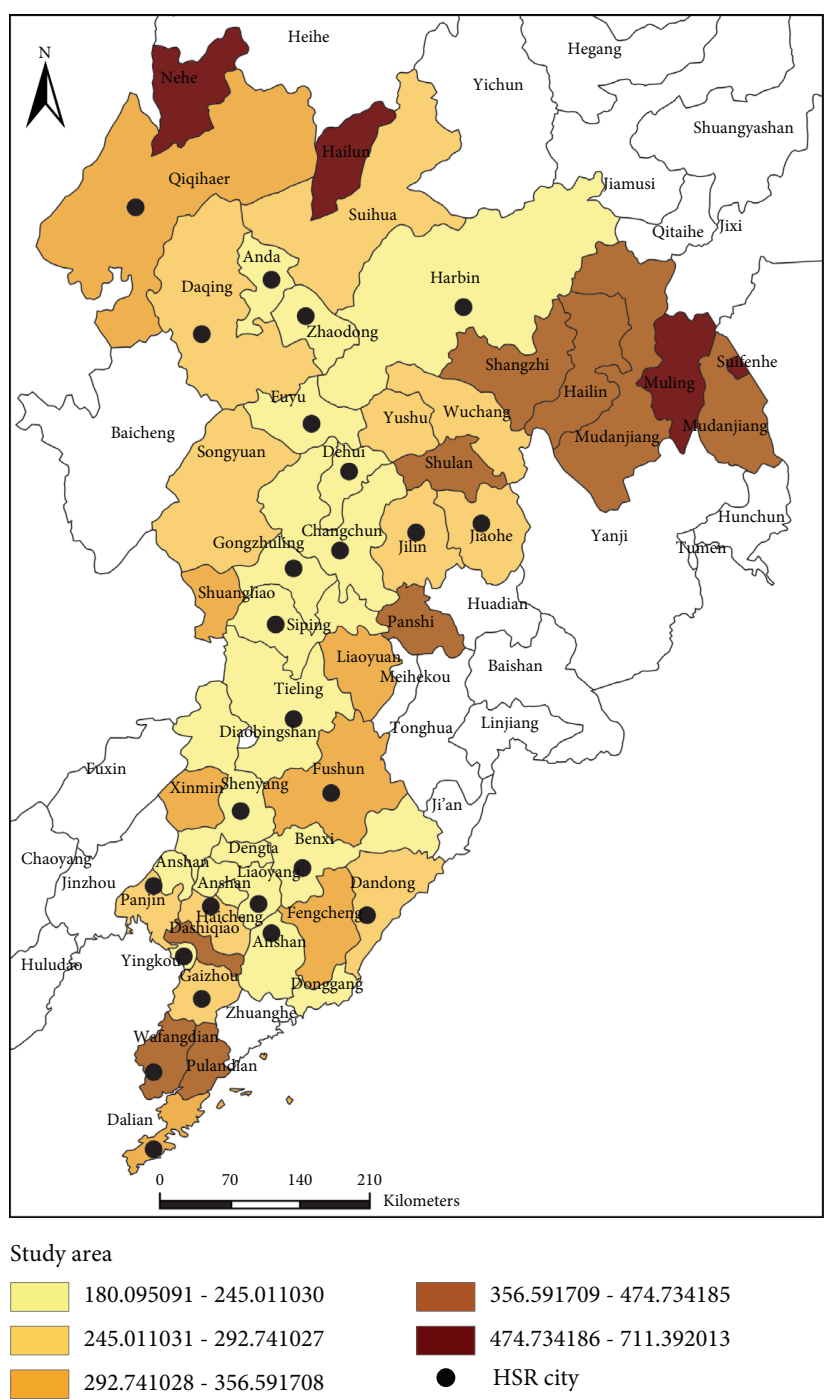

(b)

FIgURE 2: Accessibility of the study area in year 2015. (a) Normal rail and (b) HSR.

TABLE 3: Regression results of two periods.

\begin{tabular}{|c|c|c|c|c|c|}
\hline \multicolumn{3}{|c|}{$2005-2011$} & \multicolumn{3}{|c|}{$2012-2015$} \\
\hline Variable & Coefficient & Asymptote $t$-stat & Variable & Coefficient & Asymptote $t$-stat \\
\hline INV & 0.022 & 0.924 & INV & 0.069 & $2.246^{* *}$ \\
\hline GOV & 0.246 & $5.747^{* * *}$ & GOV & 0.008 & 0.210 \\
\hline EMP & -0.002 & -0.056 & EMP & -0.066 & $-2.033^{* *}$ \\
\hline ACC & -4.816 & $-9.952^{* * *}$ & ACC & -0.129 & $-2.636^{* * *}$ \\
\hline URB & 0.060 & 0.445 & URB & 0.282 & $1.461^{*}$ \\
\hline$W * \mathrm{INV}$ & -0.042 & -1.177 & $W * \mathrm{INV}$ & 0.069 & $1.670^{* *}$ \\
\hline$W * \mathrm{GOV}$ & 0.202 & $7.519^{* * *}$ & $W * \mathrm{GOV}$ & 0.074 & 1.182 \\
\hline$W * \mathrm{EMP}$ & 0.045 & 1.215 & $W * \mathrm{EMP}$ & -0.014 & -0.209 \\
\hline$W * \mathrm{ACC}$ & 0.990 & 1.369 & $W * \mathrm{ACC}$ & -0.152 & $-1.935^{* *}$ \\
\hline$W * \mathrm{URB}$ & -0.383 & $-2.169^{* *}$ & $W * \mathrm{RB}$ & 0.525 & $2.188^{* *}$ \\
\hline$W * y$ & -0.236 & $-5.308^{* * *}$ & $W * y$ & -0.236 & $-2.994^{* * *}$ \\
\hline Hausman & & $3680.782^{* * *}$ & Hausman & & $15.519^{*}$ \\
\hline LR test (spatial-fixed effects) & & $821.396^{* * *}$ & LR test (spatial-fixed & & $569.970^{* * *}$ \\
\hline LR test (time-period fixed effects) & & $31.648^{* * *}$ & LR test (time-period fi) & & $22.614^{* * *}$ \\
\hline
\end{tabular}

Note. $t$ statistics are in parentheses. ${ }^{* * *}$ Statistical significance at the $1 \%$ level. ${ }^{* *}$ Statistical significance at the $5 \%$ level. ${ }^{*}$ Statistical significance at the $10 \%$ level. 
TABLE 4: Dynamic model result.

\begin{tabular}{|c|c|c|c|c|c|c|c|c|}
\hline \multirow{2}{*}{ Variable } & \multicolumn{2}{|c|}{ Whole area } & \multicolumn{2}{|c|}{ Heilongjiang Province } & \multicolumn{2}{|c|}{ Jilin Province } & \multicolumn{2}{|c|}{ Liaoning Province } \\
\hline & Coefficient & $t$-stat & Coefficient & $t$-stat & Coefficient & $t$-stat & Coefficient & $t$-stat \\
\hline$y(t-1)$ & 0.102 & $2.394^{* *}$ & 0.122 & $1.589^{*}$ & 0.130 & $1.939^{* *}$ & 0.133 & $1.618^{*}$ \\
\hline$W * y(t-1)$ & 0.043 & $1.748^{* *}$ & 0.159 & $2.712^{* * *}$ & -0.003 & -0.069 & 0.1135 & $1.827^{* *}$ \\
\hline INV & 7.0833 & $3.629^{* * *}$ & 8.044 & $3.037^{* * *}$ & 1.216 & 0.414 & 3.228 & 0.675 \\
\hline GOV & 9.444 & $2.991^{* * *}$ & 1.664 & 0.298 & 40.754 & $4.892^{* * *}$ & 9.625 & $1.851^{* *}$ \\
\hline EMP & -1.420 & 0.598 & 0.560 & 0.088 & 13.005 & $1.825^{* *}$ & -2.482 & 0.656 \\
\hline ACC & -8.984 & $-1.978^{* *}$ & -1.695 & -0.335 & -18.827 & $-2.521^{* *}$ & -26.606 & $-2.616^{* * *}$ \\
\hline URB & 0.871 & 0.107 & 2.318 & 0.194 & 0.646 & 0.044 & 26.202 & 1.024 \\
\hline$W * y$ & 0.083 & $4.341^{* * *}$ & -0.210 & $-4.248^{* * *}$ & 0.096 & $2.378^{* *}$ & -0.222 & $-6.638^{* * *}$ \\
\hline$R^{2}$ & 0.525 & & 0.364 & & 0.677 & & 0.458 & \\
\hline
\end{tabular}

As an industry base, most cities in Northeast China made immense contribution to China, particularly in coal, steel, and petroleum. The need of the domestic market and the promulgation of government policies will greatly affect regional economic growth. As the main variable in the paper, accessibility has a negative effect on regional economic growth. This is due to the definition of accessibility above. When the value calculated by the accessibility definition is high, the connection of one city seems to be weak. It is summarized that the higher accessibility without HSR leads the economic growth to decrease. On one hand, in the perspective of factor flow, HSR connects the core cities and shortens cost so that the market scale could expand and multiple industry agglomerate could attract more labor. On the other hand, in the view of geography, the spatial connection between cities turns to be closer. The cumulative effect of circulation becomes more and more powerful.

In Northeast China, there are three provinces, Heilongjiang Province, Jilin Province, and Liaoning Province. Due to the large differences in the natural geographical attributes, location, and leading industries in the three provinces, when sampled area from different provinces, the regression results totally seem to be obviously distinctive. In the case of Heilongiiang Province, the coefficient of the one lagged in time with spatial matrix is positive and significant at $10 \%$ level. It is shown a city GDP growth will be affected by the neighboring area GDP growth of last year in this area. Nonetheless, the coefficient of dependent lagged is negative and significant at $1 \%$ level. For the sake of Heilongjiang Province is a frontier province in the north, information resources are relatively occluded. If one productive factor gathers in one area, it will definitely lead to the lack of factor needed for economic production activities in the surrounding areas. Considering the location of most cities, the technological progress is comparatively backward. Remarkably, the investment still contributes to the economic growth. If the accessibility changes 100 units, it will promote economic growth to change by $16.95 \%$. Most of the cities in the region are at the end of the railway. The improvement of transportation infrastructure has greatly reduced the time cost to other cities, and the economic growth effect is more obvious. With the time and space compression, the choice of people's travel options change, urban economic activities accelerate, economic scale expands, and the cost of production and transportation reduces. In words, these changes improve the economic efficiency and promote the regional economic growth.

When Jilin Province is used as a sample area, the coefficient of the dependent variable lagged in time, government control, employee number, and dependent variable lagged in spatial are positive and statistically significant. When concentrating on the accessibility, it passes $10 \%$ level significance test with contiguity matrix and it shows that HSR accessibility has effect on GDP growth. The elasticity coefficient of accessibility is negative 18.827, stronger effects on GDP growth than one in Heilongjiang Province. It is supposed that Jilin Province is in the middle of study area, and it could be regarded as an intermediary area. The location makes it more convenient to arrive to the other cities. Consequently, the accessibility also contributes to the GDP growth. Since the implementation of the revitalization strategy of the old industrial bases in Northeast China in 2003, the investment as a "troika" for economic growth has played an irreplaceable role in stimulating the economic growth in northeast and has effectively promoted the construction and improvement of regional infrastructure. However, since 2011, fixed-asset investment in this area has shown a downward trend. With China's macroeconomic transformation and upgrading and "de-capacity" policies, although fixed assets investment has plummeted, the longterm economic growth path exists in northeast. Dependence and mechanism and fixed asset investment is still a strong support for economic restructuring, promoting reform and realizing the transformation and upgrading of the old industrial bases in Jilin Province.

When sample from Liaoning Province, it is obtained that the coefficient of the dependent variable lagged in time is positive and statistically significant at $10 \%$. However, the coefficient of accessibility and dependent lag variable are negative and significant. As the only coastal province in Northeast, Liaoning Province is superior to the other two provinces in terms of technological advancement or innovation by its geographical location. In this condition, this area could respond to the policy of the national innovation model to drive economic growth more quickly and take effective measures to break through investment dependence. So, the investment is positive but not significant to GDP growth. From the table, it is straightforward that the elasticity of accessibility in Liaoning Province is the largest. Dalian is at the end of Ha-Da HSR. Without HSR, it takes about 10 hours at 
least to get to Dalian from Harbin. Yet, it takes only four hours by HSR. Extremely, time cost changes dramatically due to HSR. Unlike the traditional industry in this area, the service industry benefits the most because of HSR. For instance, the main industries in Zhuanghe (one city in Liaoning Province) are agriculture and tourism. Since the high-speed rail was opened to traffic in 2012, the tourism industry has attracted more tourists and promoted the development of tourism. At the same time, due to the geographical location, fruit planting is also one of the characteristics of Zhuanghe. The rapid development of facilities will reduce transportation costs and will also promote regional economic development.

As the old industrial bases in Northeast China, stateowned enterprises account for a large proportion, and private enterprises account for a relatively small proportion. Therefore, the government participates in regional economic activities to a greater extent. Under the leadership of government policies and the degree of openness and the Harbin Changchun Urban Agglomeration and Central and Southern Liaoning Urban Agglomeration as the economic growth pole of the region, government intervention is mainly aimed at pursuing the improvement of economic efficiency in the region, while ignoring the division of labor between regions. The problem of resource allocation may lead to excessive competition between regions. The market competition mechanism may be higher than the government behavior. Conducive to the improvement of economic efficiency is not conducive to the formation of a stable network between cities, weakening the interaction between regional economic growth, so that factor flow can not break through the boundaries of barriers.

In general, the regression coefficient of accessibility is relatively large to regional economic growth which is believed that the HSR really prospers the regional economic growth in Northeast China, especially in Liaoning Province but works least in Heilongjiang Province. And, in terms of the dynamic econometric model result, the time lag and spatial-time lag variables contribute to the economic growth in this study area, but the coefficients are relatively small. It is supposed that the area in Northeast China may be getting rid of economic growth from itself dependence. The coefficient of accessibility is relatively large to regional economic growth which means that HSR could make the economic growth in this area which maintains the same as in Yangtze River Delta and Beijing-Tianjin-Hebei region.

\section{Conclusions}

In recent years, Northeast China is experiencing some socioeconomic problems, including population loss, outdated economic structure, and lack of technological innovation. As the old industrial bases in the past, the three provinces in Northeast China are still heavily affected by the residue of planned economy.

The stimulation policy has sought to improve the situation in this area via infrastructure investment. This study uses the spatial econometric method to assess the effect of this stimulation policy. First, it is found that the accessibility is increased significantly by the HSR construction. However, the accessibility of county-level cities still falls smaller than that of main cities. Second, as all other regions, investment values contribute to the regional economic growth. When the investment growth increases by one unit, GDP growth will increase around 7\%. It is worth to make capital expenditure expansion in tourism, which easily drives other industries' development, such as accommodation and catering. Specially, the study area is famous for the ice-snow scenery in winter, and it is an effective way to invigorate the economic growth by daytrips or weekend trips with HSR [63]. From this perspective, it is worth considering more investment in this industrial sector. Third, the transportation infrastructure spillover effect is positive and significant. It confirms that the nearby areas will influence each other in accessibility and economic growth. Conforming to some previous research, it is shown that transportation infrastructure can generate spillover effects on production [64]. It is reasonable to invest more to the infrastructure development.

Currently, the basic network of HSR is completed in China. However, in the peripheral regions like Northeast region in China, the HSR only connects some main cities and the investment is much less than the coastal regions. According to the results, it is necessary to construct the HSR to connect more cities to stimulate the capital flow. Overall, the general conclusion is that infrastructure construction can improve the connection of the main cities and surrounding cities via spillover effects. This accelerates the labor and capital flow, stimulates the economy, and encourages the development of core-periphery structure or urban agglomeration. The infrastructure investment has strong and positive effects even in the economically challenging areas experiencing population loss.

With the HSR network completed, it is necessary to optimize the economic growth structure, improve the efficiency of factor capital space allocation, and promote the spatial coordinated development among the three provinces. Although the factors have significant neighboring effects in geography, creating conditions for spatially adjacent regional cross-regional synergy, the spatial correlation of cities economic growth presents a complex network structure which provides interprovincial coordination mechanisms from the relationship of cities. On the one hand, we should further promote the role of the government's macrocontrol mechanism in promoting the spatial relationship of the economy. With the second round of "revitalizing the old industrial bases in Northeast China," we should actively respond to the Belt and Road Initiative to promote the spatial allocation of space and the optimization of spatial linkages to realize the interconnection of the economic activities in study area. In addition, it is necessary to recognize the differences of economic development mode and industrial structure and use the decisive role of the market in factor allocation to minimize the government intervention in the market, through price, competition, supply, and demand.

\section{Data Availability}

The travel time between two cities before and after HSR construction is collected from the official website of 12306 
China Railway. Other socioeconomic data are collected from the China City Statistical Yearbook, Heilongjiang Statistical Yearbook, Jilin Statistical Yearbook, and Liaoning Statistical Yearbook.

\section{Conflicts of Interest}

The authors declare that they have no conflicts of interest.

\section{Acknowledgments}

This work was supported by the National Natural Science Foundation of China, Nos. 41630749, 42001117, 41801153, 42071219 , and 41771126 .

\section{References}

[1] M. Diao, "Does growth follow the rail? The potential impact of high-speed rail on the economic geography of China," Transportation Research Part A: Policy and Practice, vol. 113, no. 6, pp. 279-290, 2018.

[2] X. Fan, D. Zheng, and M. Shi, "How does land development promote China's urban economic growth? The mediating effect of public infrastructure," Sustainability, vol. 8, no. 3, pp. 279-290, 2016.

[3] C. Sun, Y. Yang, and L. Zhao, "Economic spillover effects in the Bohai Rim Region of China: is the economic growth of coastal counties beneficial for the whole area?" China Economic Review, vol. 33, no. 4, pp. 123-136, 2015.

[4] L. Wang, "High-speed rail services development and regional accessibility restructuring in megaregions: a case of the Yangtze River Delta, China," Transport Policy, vol. 72, no. 12, pp. 34-44, 2018.

[5] Y.-J. Zhang, Z. Liu, S.-M. Zhou, C.-X. Qin, and H. Zhang, "The impact of China's Central Rise Policy on carbon emissions at the stage of operation in road sector," Economic Modelling, vol. 71, no. 4, pp. 159-173, 2018.

[6] F. Xiong, "Analysis on the causes and countermeasures of the economic predicament in the Northeast China," Modern Economy, vol. 7, no. 9, pp. 1014-1019, 2016.

[7] H. Guan, W. Liu, P. Zhang, K. Lo, J. Li, and L. Li, "Analyzing industrial structure evolution of old industrial cities using evolutionary resilience theory: a case study in Shenyang of China," Chinese Geographical Science, vol. 28, no. 3, pp. 516-528, 2018.

[8] P. Arbués, J. F. Baños, and M. Mayor, "The spatial productivity of transportation infrastructure," Transportation Research Part A: Policy and Practice, vol. 75, no. 5, pp. 166-177, 2015.

[9] J. P. Cohen and C. J. M. Paul, "Public infrastructure investment, interstate spatial spillovers, and manufacturing costs," Review of Economics and Statistics, vol. 86, no. 2, pp. 551-560, 2004.

[10] N. Chu, P. Zhang, H. Li, and B. Jiang, "Pattern characteristics and evolution trend of intercity high-speed rail network in Northeast China," Scientia Geographica Sinica, vol. 39, no. 5, pp. 761-769, 2019.

[11] J. Guo, S. Wang, H. Wang, and T. Liu, "Impact of HarbinDalian high-speed railway on the spatial distribution of tourism supply and demand markets in Northeast China cities: based on the accessibility of the scenic spots," Progress in Geography, vol. 35, no. 4, pp. 505-514, 2016.
[12] W. G. Hansen, "How accessibility shapes land use," Journal of the American Institute of Planners, vol. 25, no. 2, pp. 73-76, 1959.

[13] J. M. Morris, P. L. Dumble, and M. R. Wigan, “Accessibility indicators for transport planning," Transportation Research Part A: General, vol. 13, no. 2, pp. 91-109, 1979.

[14] K.-W. Tsou, H.-T. Cheng, and F.-Y. Tseng, "Exploring the relationship between multilevel highway networks and local development patterns-a case study of Taiwan," Journal of Transport Geography, vol. 43, no. 2, pp. 160-170, 2015.

[15] J. Y. Go and S. Lee, "An appraisal of the urban scheme for sustainable urban transport," International Journal of Urban Sciences, vol. 16, no. 3, pp. 261-278, 2012.

[16] S. L. Handy and K. J. Clifton, "Evaluating neighborhood accessibility: possibilities and practicalities," Journal of Transportation and Statistics, vol. 4, no. 2, pp. 67-78, 2001.

[17] D. M. Levinson, "Accessibility and the journey to work," Journal of Transport Geography, vol. 6, no. 1, pp. 11-21, 1998.

[18] J. Gutiérrez, "Location, economic potential and daily accessibility: an analysis of the accessibility impact of the highspeed line Madrid-Barcelona-French border," Journal of Transport Geography, vol. 9, no. 4, pp. 229-242, 2001.

[19] Q. Hou and S.-M. Li, "Transport infrastructure development and changing spatial accessibility in the Greater Pearl River Delta, China, 1990-2020," Journal of Transport Geography, vol. 19, no. 6, pp. 1350-1360, 2011.

[20] G. M. Ahlfeldt and N. Wendland, "Fifty years of urban accessibility: the impact of the urban railway network on the land gradient in Berlin 1890-1936," Regional Science and Urban Economics, vol. 41, no. 2, pp. 77-88, 2011.

[21] J. Dubé, M. Thériault, and F. Des Rosiers, "Commuter rail accessibility and house values: the case of the Montreal South Shore, Canada, 1992-2009," Transportation Research Part A: Policy and Practice, vol. 54, no. 8, pp. 49-66, 2013.

[22] L. Osland and I. Thorsen, "Spatial impacts, local labour market characteristics and housing prices," Urban Studies, vol. 50, no. 10, pp. 2063-2083, 2013.

[23] M. W. Horner, "Exploring metropolitan accessibility and urban structure," Urban Geography, vol. 25, no. 3, pp. 264-284, 2004.

[24] Q. Li, T. Zhang, H. Wang, and Z. Zeng, "Dynamic accessibility mapping using floating car data: a network-constrained density estimation approach," Journal of Transport Geography, vol. 19, no. 3, pp. 379-393, 2011.

[25] J. Grengs, "Job accessibility and the modal mismatch in Detroit," Journal of Transport Geography, vol. 18, no. 1, pp. 42-54, 2010.

[26] J. Shi and N. Zhou, "How cities influenced by high speed rail development: a case study in China," Journal of Transportation Technologies, vol. 3, no. 2, pp. 7-16, 2013.

[27] J. Li, "Survey and analysis on passenger travel characteristics and distribution features of Wuhan-Guangzhou high speed railway," Railway Standard Design, vol. 53, no. 11, pp. 1-4, 2011.

[28] D. M. Levinson, "Accessibility impacts of high-speed rail," Journal of Transport Geography, vol. 22, no. 5, pp. 288-291, 2012.

[29] J. Jiao, J. Wang, F. Zhang, F. Jin, and W. Liu, "Roles of accessibility, connectivity and spatial interdependence in realizing the economic impact of high-speed rail: evidence from China," Transport Policy, vol. 91, no. 6, pp. 1-15, 2020.

[30] J. Jiao, J. Wang, F. Jin, and M. Dunford, "Impacts on accessibility of China's present and future HSR network," 
Journal of Transport Geography, vol. 40, no. 10, pp. 123-132, 2014.

[31] Z. Chen and K. E. Haynes, "Impact of high-speed rail on regional economic disparity in China," Journal of Transport Geography, vol. 65, no. 12, pp. 80-91, 2017.

[32] S. Wang, J. Guo, X. Luo, J. Liu, and Z. Gu, "Spatial impact of high-speed railway on the urban scale: an empirical analysis from Northeast China," Chinese Geographical Science, vol. 30, no. 2, pp. 366-378, 2020.

[33] J. Gutiérrez, A. Condeço-Melhorado, and J. C. Martín, “Using accessibility indicators and GIS to assess spatial spillovers of transport infrastructure investment," Journal of Transport Geography, vol. 18, no. 1, pp. 141-152, 2010.

[34] D. A. Aschauer, "Is public expenditure productive?," Journal of Monetary Economics, vol. 23, no. 2, pp. 177-200, 1989.

[35] R. L. Moomaw, J. K. Mullen, and M. Williams, "The interregional impact of infrastructure capital," Southern Economic Journal, vol. 61, no. 3, pp. 830-845, 1995.

[36] T. R. Lakshmanan, "The broader economic consequences of transport infrastructure investments," Journal of Transport Geography, vol. 19, no. 1, pp. 1-12, 2011.

[37] C. Shirley and C. Winston, "Firm inventory behavior and the returns from highway infrastructure investments," Journal of Urban Economics, vol. 55, no. 2, pp. 398-415, 2004.

[38] X. Zhang, "Has transport infrastructure promoted regional economic growth? With an analysis of the spatial spillover effects of transport infrastructure," Social Sciences in China, vol. 34, no. 2, pp. 24-47, 2013.

[39] M. J. Delgado and I. Álvarez, "Network infrastructure spillover in private productive sectors: evidence from Spanish high capacity roads," Applied Economics, vol. 39, no. 12, pp. 1583-1597, 2007.

[40] N. Yu, M. de Jong, S. Storm, and J. Mi, "Spatial spillover effects of transport infrastructure: evidence from Chinese regions," Journal of Transport Geography, vol. 28, no. 4, pp. 56-66, 2013.

[41] A. Comber, C. Brunsdon, and E. Green, "Using a GIS-based network analysis to determine urban greenspace accessibility for different ethnic and religious groups," Landscape and Urban Planning, vol. 86, no. 1, pp. 103-114, 2008.

[42] J. Cohen and K. Monaco, "Ports and highways infrastructure," International Regional Science Review, vol. 31, no. 3, pp. 257-274, 2008.

[43] B. W. Sloboda and V. W. Yao, "Interstate spillovers of private capital and public spending," The Annals of Regional Science, vol. 42, no. 3, pp. 505-518, 2008.

[44] R. Moreno and E. López-Bazo, "Returns to local and transport infrastructure under regional spillovers," International Regional Science Review, vol. 30, no. 1, pp. 47-71, 2007.

[45] B. Zhu, J. He, and S. Zhai, "Does financial inclusion create a spatial spillover effect between regions? Evidence from China," Emerging Markets Finance \& Trade, vol. 55, no. 4, pp. 980-997, 2019.

[46] B. Meng, J. Wang, R. Andrew, H. Xiao, J. Xue, and G. P. Peters, "Spatial spillover effects in determining China's regional $\mathrm{CO}_{2}$ emissions growth: 2007-2010," Energy Economics, vol. 63, no. 3, pp. 161-173, 2017.

[47] X. Chen, S. Shao, Z. Tian, Z. Xie, and P. Yin, "Impacts of air pollution and its spatial spillover effect on public health based on China's big data sample," Journal of Cleaner Production, vol. 142, no. 2, pp. 915-925, 2017.

[48] T. T. Thang, T. S. H. Pham, and B. R. Barnes, "Spatial spillover effects from foreign direct investment in Vietnam," The Journal of Development Studies, vol. 52, no. 10, pp. 1431-1445, 2016.
[49] R. Xie, J. Fang, and C. Liu, "Impact and spatial spillover effect of transport infrastructure on urban environment," Energy Procedia, vol. 104, no. 12, pp. 227-232, 2016.

[50] L.-F. Lee and J. Yu, "A spatial dynamic panel data model with both time and individual fixed effects," Econometric Theory, vol. 26, no. 2, pp. 564-597, 2010.

[51] J. Dubé, D. Legros, M. Thériault, and F. Des Rosiers, “A spatial difference-in-differences estimator to evaluate the effect of change in public mass transit systems on house prices," Transportation Research Part B: Methodological, vol. 64, no. 6, pp. 24-40, 2014.

[52] T. Tong, T.-H. E. Yu, S.-H. Cho, K. Jensen, and D. De La Torre Ugarte, "Evaluating the spatial spillover effects of transportation infrastructure on agricultural output across the United States," Journal of Transport Geography, vol. 30, no. 6, pp. 47-55, 2013.

[53] J. Yang, A. Guo, X. Li, and T. Huang, "Study of the impact of a high-speed railway opening on China's accessibility pattern and spatial equality," Sustainability, vol. 10, no. 8, pp. 2943-2956, 2018.

[54] D. Efthymiou and C. Antoniou, "How do transport infrastructure and policies affect house prices and rents? Evidence from Athens, Greece," Transportation Research Part A: Policy and Practice, vol. 52, no. 2, pp. 1-22, 2013.

[55] C. F. Del Bo and M. Florio, "Infrastructure and growth in a spatial framework: evidence from the EU regions," European Planning Studies, vol. 20, no. 8, pp. 1393-1414, 2012.

[56] S.-H. Cho, R. K. Roberts, and S. G. Kim, "Negative externalities on property values resulting from water impairment: the case of the Pigeon River Watershed," Ecological Economics, vol. 70, no. 12, pp. 2390-2399, 2011.

[57] K. Haandrikman, L. J. G. van Wissen, and C. N. Harmsen, "Explaining spatial homogamy. Compositional, spatial and regional cultural determinants of regional patterns of spatial homogamy in The Netherlands," Applied Spatial Analysis and Policy, vol. 4, no. 2, pp. 75-93, 2011.

[58] X. Li, X. Hu, S. Shi, L. Shen, L. Luan, and Y. Ma, "Spatiotemporal variations and regional transport of air pollutants in two urban agglomerations in Northeast China plain," Chinese Geographical Science, vol. 29, no. 6, pp. 917-933, 2019.

[59] J.-P. Bénassy, "Price level determinacy under a pure interest rate peg," Review of Economic Dynamics, vol. 3, no. 1, pp. 194-211, 2000.

[60] M. Lettau and H. Uhlig, "Can habit formation be reconciled with business cycle facts?," Review of Economic Dynamics, vol. 3, no. 1, pp. 79-99, 2000.

[61] B. Alexander, D. Ettema, and M. Dijst, "Fragmentation of work activity as a multi-dimensional construct and its association with ICT, employment and sociodemographic characteristics," Journal of Transport Geography, vol. 18, no. 1, pp. 55-64, 2010.

[62] M. Yu and W. Fan, "Accessibility impact of future high speed rail corridor on the piedmont Atlantic megaregion," Journal of Transport Geography, vol. 73, no. 12, pp. 1-12, 2018.

[63] S. Jin, J. Yang, E. Wang, and J. Liu, "The influence of highspeed rail on ice-snow tourism in Northeastern China," Tourism Management, vol. 78, Article ID 104070, 2020.

[64] P. Arbués and J. F. Baños, "A dynamic approach to road freight flows modeling in Spain," Transportation, vol. 43, no. 3, pp. 549-564, 2016. 